\title{
Impact of pharmaceutical counseling in minor health problems in rural Portugal
}

Raquel B. COELHO, Filipa A. COSTA.

Received (first version): 12-Apr-2014 Accepted: 6-Oct-2014

\begin{abstract}
${ }^{*}$
Objectives: The objectives of this study were to determine the prevalence of self-medication and to evaluate the clinical impact of pharmaceutical counseling.

Methods: A cross-sectional study was used with a prospective component, the latter to evaluate the impact of pharmaceutical counseling. The study was conducted in a rural community pharmacy for 14 consecutive days in December 2012, recruiting all individuals who agreed to participate and met the eligibility criteria. During a face-toface direct interview demographic and clinical characteristics of patients were registered, followed by a pharmaceutical intervention, which consisted of evaluating the symptoms, selecting the most appropriate nonprescription medicine (NPM) available and advising the patient on pharmacologic and non-pharmacologic measures, all according to established protocols for minor health problems. When appropriate, the patient was referred to a medical appointment. One week later, the clinical outcome of such intervention was measured by asking the patients about the resolution of their minor health problems.

Results: Data from 298 patients were analyzed, the majority being female $(60.1 \%)$ with an average age of 44.84 years $(S D=22.41)$. Respiratory problems were the most frequent $(n=78 ; 26.2 \%)$ and respiratory tract medication was the most frequently indicated $(n=77$; $27.8 \%$ ). The observed prevalence of self-medication was $40.7 \%$. Of the 271 patients' beneficiaries of pharmaceutical counseling, $86.8 \%$ had their minor health problems solved after one week (ranging from $77.5 \%$ to $88.2 \%$ according to a sensibility analysis for drop-outs). Conclusions: This work is important as it demonstrates the beneficial impact of pharmaceutical counseling, a very relevant area for the pharmacist and where literature is particularly scarce.
\end{abstract}

Keywords: Nonprescription Drugs; Counseling; Community Pharmacy Services; Professional Practice; Pharmacists; Portugal

\footnotetext{
*Raquel Batista COELHO. Master in Pharmaceutical Sciences. Pharmaceutical Care Specialist, Pharmacy in Pharmaceutical Alfeirão. Vila Nova de Milfontes (Portugal). rakacoelho@hotmail.com

Filipa Alves da COSTA. PhD in Pharmacy., Assistant Professor, Higher Institute of Health Sciences Egas Moniz. Centre for Interdisciplinary Research Egas Moniz (CiiEM). Almada (Portugal). alvesdacosta.f@gmail.com
}

\section{INTRODUCTION}

Pharmaceutical counseling in minor health disorders aims at improving and/ or solving minor symptoms experienced by patients under selfmedication. The pharmacist has a key role in selecting the most appropriate therapy and educating the patient for self-care in order to achieve positive clinical outcomes, reducing health care costs and preventing possible drug-relatedproblems.

There is no agreement on the likely situations that can be treated using self-medication in Europe. ${ }^{1}$ However, in Portugal, the Medical Doctors Society and the Pharmaceutical Society sought an agreement and it can be said that there are currently 66 situations that can be handled by the pharmacist using non-prescription medicines (NPMs) which are mentioned in the Legal Dispatch no. $17690 / 2007$, published on the $23^{\text {rd }}$ of July. ${ }^{2}$

The easy access to the pharmacy, both in terms of geographical distribution and in terms of the counseling service gratuity, makes it the setting of choice for many patients that seek early resolution of their minor health problems. ${ }^{3}$ The pharmacist's crucial role is to inform the patient on the correct use of the product. It is described that the misuse of NPMs is responsible for over 170.000 hospitalizations per year in the US, corresponding to an annual cost of USD750 million. More troubling is the reported data that half of these hospitalizations could have been prevented through more effective education and information directed to consumers. ${ }^{4}$ In Portugal, NPMs may be displayed and advertised, but cannot be purchased as a selfservice good since they may only be placed behind the counter in a reserved area where only the pharmaceutical team can reach. ${ }^{5}$

Self-medication may be achieved by using nonprescription medicines but also by using herbal medicines or dietary supplements. The two later however do not follow the same above mentioned rule as they may be placed in an area of the pharmacy directly reached by the public. Additionally, the legal dispatch mentioned also does not cover for these categories, therefore pharmacists do not resort to them as often as they do to NPMs.

There are several studies that characterize the current of NPMs in terms of prevalence of selfmedication. Two Portuguese studies have researched this topic, presenting estimates of the prevalence of self-medication of $26.2 \%$ and $21.5 \%$, respectively for urban and rural populations., Figueiras et al. conducted a study in Spain, 
indicating a much lower prevalence of selfmedication, reported to be $12.7 \% .^{8}$ More in line with Portuguese data, the work by Schmid et al. conducted in Brazil found a prevalence of around $30 \%{ }^{9}$ Totally unexpected results in this same country have been reported by Vosgerau et al., suggesting it to go as high as $67.1 \%{ }^{10}$ All these studies are cross-sectional studies. Studies of Melo et al and Martins et al evaluated the current use of the drug. The study Vosgerau et al. evaluated the use of the drug over 7 days and the studies of Schmid et al. and Figueiras et al. evaluated the use of the drug over 15 days and 14 days respectively. There are three necessary stages in the pharmaceutical counseling process: stage I clinical interview of the patient, stage II pharmaceutical intervention and stage III assessing patient's clinical outcomes. ${ }^{1,11-14}$ As the pharmacist is the main source of information for patients when they selfmedicate, his intervention is important so that selfmedication is conducted in a safe, effective and rational manner. ${ }^{15}$

The literature is scarce in demonstrating the impact of pharmaceutical counseling in minor health problems on patient's health. Some studies in this context worth mentioning include the work by Krishnan and Shaefer, which has shown that patients suffering from dyspepsia have reported an average increase of $13.6 \%$ in their quality of life based on the pharmacological and nonpharmacological advice given by pharmacists. ${ }^{16}$ Sclar et al. have conducted a study in 23 pharmacies in the Washington state and when evaluating the pharmacy services with NPMs concluded that pharmaceutical interventions have prevented adverse, additional and collateral side effects, as well as medical interaction and therapeutical duplication in $7.1 \%$ of the 745 NPM consumers. ${ }^{17}$ In a study by Bosse et al., the reported impact on a 83 patient sample was positive in $82.6 \%$, assessed by reported symptom relief. ${ }^{4}$

There is not much research that explicitly approach the prevalence of pharmaceutical counseling. Pharmaceutical counseling may be defined as the explicit request from a patient to receive advice from a pharmacist. Some studies have used the term "symptom-based request", as opposed to "productbased request", the latter being coincident with the reports of self-medication, i.e., the patient is the one selecting how to treat his minor health problem. ${ }^{18}$

The prevalence of pharmaceutical counseling in the case study by Martins ${ }^{6}$ was of $50 \%$, since half of the patients requested pharmacist's counseling. In studies by Nunes de Melo ${ }^{7}$ and Nicole Bosse ${ }^{4}$ the prevalence of pharmaceutical counseling was lower, $47.2 \%$ and $40.1 \%$ respectively. The prevalence of pharmaceutical counseling depends on the patients' recognition of the pharmacist as a health professional able to solve their health issues. ${ }^{19,20}$

In the work by Wazaify et al. it is stated that $78 \%$ of the general public believes that pharmacists play a key role in supplying and counseling about the safety and effectiveness of NPMs and $63 \%$ say that they look for pharmaceutical counseling to solve minor health problems. ${ }^{19}$ In the study by You et al
$68 \%$ of patients agree to consult the pharmacist before using a NPM, thus promoting its correct use. $^{20}$

This way, it is pointed out that the pharmaceutical intervention is part of an educational process of patients to self-care when they present themselves at the community pharmacy to solve and/ or prevent their minor health problems on a self-medication basis. It is important to measure the impact of this intervention and to estimate the proportion of patients that usually resort to this pharmaceutical service aiming at its differentiation.

Literature search undertaken demonstrates that there are few studies focusing on the impact of pharmaceutical intervention in terms of essential services. $^{4,16,17}$ There is vast literature looking at enhanced services, such as medication review or pharmaceutical care. ${ }^{21-25}$ However, the level of implementation of essential services is far wider than of enhanced services. ${ }^{26,27}$ Therefore, this study aims at filling in the gap by trying to establish the importance of pharmacists' interventions in daily practice.

\section{METHODS}

\section{Study design and setting}

An intervention study with pre-post analysis was conducted between the $3^{\text {rd }}$ and $16^{\text {th }}$ of December 2012 in one community pharmacy, Farmácia Alfeirão, located in Vila Nova de Milfontes, Alentejo, Portugal.

\section{Population and patient sample}

The study population considered was all patients who attended this pharmacy during the aforementioned time period and met21the inclusion criteria.

Inclusion criteria were defined as presenting at the pharmacy with at least one minor symptom or directly asking for an NPMs for their personal use. Both cases were considered to be self-medication as they resulted in the current use of NPMs, referred to prevalence of self-medication.

To estimate the sample size, Epi Info, edition 7 was used, considering a total population of 2532 inhabitants (as defined by law ${ }^{28}$ ), prevalence of selfmedication $^{7}$ of $21.5 \%$ and the standard beta and alpha errors, indicating 235 patients were needed.

\section{Patient recruitment}

Patients were individually invited to participate in this survey by the working team of Pharmacy Alfeirão. All members of the team were duly trained for patient recruitment. At this point, patients were given information about the study and, after reading and signing the informed consent form, they were referred to the main pharmacist. One single pharmacist conducted all the interviews and provided pharmaceutical counseling. The same pharmacist was responsible for conducting the follow-up interviews after one week, to all patients providing contact information for such purpose. 


\section{Intervention}

All interventions were conducted by the pharmacist in charge. The intervention consisted of three stages. The first was the clinical interview to the patient where biographical data (age and gender) were registered, the situation that led the patient to seek the pharmacy (asking directly for the drug or asking advice from the pharmacist) and the reason of the consultation (patient's minor health problem), considering five key questions for assessing the situation, known as "WWHAM questions".

During the second stage (pharmaceutical intervention), the patient's minor health problem were assessed and it was decided, based on exclusion criteria for self-medication, to refer or not patients for medical appointment. ${ }^{11-13}$ The patients not referred for medical care were targeted for pharmaceutical counseling. At this stage, the pharmacist selected the most appropriate therapy (non-pharmacological measures or pharmacological treatment) ${ }^{11,12,14}$ best suited considering established criteria of efficiency, safety, cost and convenience $^{11,31}$ and educated the patient for selfcare.

Non-pharmacological measures consist of treatments that may be used solely or supplementary to therapy that will accelerate recovery. Some examples are moisture, steam, and the rest of the voice in cases of acute hoarseness for casual vocal effort or non-pharmacological eyelid hygiene and application of moist and warm compresses in blepharitis.

The third stage consisted on the assessment of the patient's clinical outcomes by pharmaceutical or medical intervention, after a week, questioning the patient about the perception on his/ her symptoms' improvement (whether he/ she got nothing, a little, or much better). The patients, who were referred to medical consultation, were also asked if they already had their appointment or if they were still waiting. Should the appointment already have happened, the assessment made on symptom perception was exactly the same.

This pharmaceutical intervention was performed following the guidance established in Rule 5 of Good Pharmacy Practice ${ }^{11}$, which refers to the stages and processes to be followed when counseling patients under a self-medication regime (Pharmacists Association and National Association of Pharmacies). ${ }^{32,33}$ Further support has been obtained from the Protocols of Practice for minor disorders developed by the above mentioned representative organizations. ${ }^{32,33}$ Whenever it was considered there were gaps in these protocols, a reference book for community pharmacy has been used "Non-prescription drugs - pharmaceutical Counseling".

\section{Data collection}

All study patients were analyzed in terms of sociodemographic variables, reason for consultation mentioned by the patient, assessment of the minor condition by the pharmacist, description of the pharmaceutical counseling and results of the pharmaceutical and medical indication evaluated after one week, anticipating the possibility of data collection face-to-face or by telephone.

The Anatomical Therapeutic Chemical classification was used, collecting the first level rating code to classify indicated medicines. ${ }^{34}$

These variables were collected using a service record sheet specifically developed for this project to assist the pharmacist in the process of pharmaceutical counseling. The sheet comprised two stages of data collection, seven days apart, through individual face-to-face interviews during the first week and in person or by telephone during the second week of the study.

The communication method between patient and pharmacist was registered. Patients impossible to reach after three telephone contact attempts or those missing appointment were considered lost to follow-up and excluded from the analysis. The established protocol for such attempts considered a 24-hour interval and was always undertaken at the time requested by the patient. Minor-aged patients received pharmaceutical counseling in the presence of an adult caregiver.

\section{Statistical analysis}

Statistical analysis was undertaken using SPSS edition 21.0 (Statistical Package for Social Sciences).

To characterize the studied sample and evaluate the proportion of patients that resorted to pharmaceutical counseling, descriptive univariate analysis was used, comprising central tendency, dispersion and shape measures for quantitative variables and absolute and relative frequencies for qualitative variables.

Prevalence of self-medication was considered as the current use of NPMs and was estimated considering all patients who met the inclusion criteria as numerator and all patients who during the study period entered the pharmacy as the denominator. This enabled the estimation of current use of NPMs, in the future referred as prevalence of self-medication.

Bivariate analysis was used to assess the impact of pharmaceutical counseling, by means of paired samples t-tests for continuous variables and chisquared tests for categorical variables. The choice of parametric statistical tests is justified by sample size and the verification of data normality distribution assessed by the Kolmogorov-Smirnov test.

Sensitivity analysis was used to account for the effects of patients lost to follow-up, where a worstcase scenario and the opposite were considered. A confidence level of $95 \%$ was considered for all tests.

\section{Ethics and confidentiality}

All the requirements of ethics and confidentiality of the data were completed; hence the researchers have resorted to a statement of informed consent signed by the participants. Patients' records with 


\begin{tabular}{|c|c|c|c|}
\hline $\begin{array}{l}\text { Health problems presented by the } \\
\text { patients }\end{array}$ & $\begin{array}{l}\text { Absolute frequency } \\
(\mathrm{n})\end{array}$ & $\begin{array}{l}\text { Relative frequency } \\
(\%)\end{array}$ & Total \\
\hline Digestive & 62 & 20.8 & $20.8(100.0)$ \\
\hline Respiratory & 78 & 26.2 & $26.2(100.0)$ \\
\hline Dermal & 57 & 19.1 & $19.1(100.0)$ \\
\hline Nervous system & 39 & 13.1 & $13.1(100.0)$ \\
\hline Bone/muscle & 46 & 15.4 & $15.4(100.0)$ \\
\hline Fever & 6 & 2.0 & $2.0(100.0)$ \\
\hline Asthenia & 2 & 0.7 & $0.7(100.0)$ \\
\hline Avitaminosis & 8 & 2.7 & $2.7(100.0)$ \\
\hline Ocular & 8 & 2.7 & $2.7(100.0)$ \\
\hline Gynecologist & 12 & 4.0 & $4.0(100.0)$ \\
\hline Vascular & 5 & 1.7 & $1.7(100.0)$ \\
\hline
\end{tabular}

their personal information were coded and kept separately to preserve the anonymity and confidentiality.

Since the study is subdivided in a longitudinal and cross-sectional component, only patients who authorized participation in the longitudinal component were requested contact details data. In either case, the statement of informed consent was conceived in order to be placed on top of the record sheet of the pharmaceutical prompt service, being detachable so that it was not possible to associate the personal data of the patient to the information contained in the record sheet.

The technical director of the pharmacy where the study was developed also signed an authorization for study development.

The study has been approved by the Ethics Committee of the Institute of Health Sciences Egas Moniz (ISCSEM).

\section{RESULTS}

The population sample consisted of 731 patients who attended the pharmacy during the study period. The sample of interest, i.e., patients who were carriers of at least a minor disorder meeting the inclusion criteria, was 298 patients.

In this study, the prevalence of self-medication was $40.7 \%\left(298 /(731)^{*} 100 \%\right)$, these being potential candidates for pharmaceutical counseling.

When analyzing the results, the patient's request for pharmacist advice superseded $(n=153,51.3 \%)$ patients presenting themselves at the pharmacy with a direct-product request ( $n=145,48.7 \%)$.

It was mostly women who sought the pharmacy $(n=179,60.1 \%)$ to solve their minor health problems in self-medication scheme.
The mean age was 44.84 years $(S D=22.41)$ and the age group that most resorted to self-medication was aged between 26 and 49 years $(n=147,49.3 \%)$.

The most frequent health problems were respiratory $(26.2 \%)$, followed by digestive $(20.8 \%)$, skin $(19.1 \%)$, muscle or bone $(15.4 \%)$, and finally nervous system problems (13.1\%) (Table 1$)$.

The majority of patients had only one health problem on their first visit to the pharmacy $(n=274$, 91.9\%), 207 patients (69.5\%) had not yet used any medicine for that health problem. Among the remaining 91 patients who were using or had previously used medicines for the presenting health problems, 59 did so by their own initiative $(61.5 \%$ of them exclusively singled out this option) and 37 did so following a medical prescription $(38.5 \%$ who indicated only this option). It is important to point out, there were 5 patients $(5.5 \%)$ that indicated the two options, i.e., they did it for the two aforementioned reasons.

The majority of patients $(n=169 ; 56.7 \%)$ were taking other medicines at the time. Of these, 81 patients $(44.8 \%)$ reported that it was due to chronic condition, $41(22.6 \%)$ because of another occasional health problem and $59(32.6 \%)$ reported taking them preventively. It should also be documented that there were 12 patients $(7.1 \%)$ who reported the two previous answers. A minority of patients $(n=27 ; 9.1 \%)$ were referred to the doctor, and the remaining $271 \quad(90.9 \%)$ received pharmaceutical counseling for their problem.

For patients that received pharmaceutical counseling, the majority were indicated drug therapy $(n=147,49.3 \%)$ and only 20 patients received exclusively non-pharmacological measures $(6.7 \%)$. Pharmaceutical counseling included both for 131 patients $(44.0 \%)$.

The main therapeutic groups advised in the context of pharmaceutical counseling to the 277 patients

\begin{tabular}{|c|c|c|c|}
\hline Different therapeutic groups purchased by patients & $\begin{array}{l}\text { Absolute frequency } \\
(\mathrm{n})\end{array}$ & $\begin{array}{l}\text { Relative frequency } \\
(\%)\end{array}$ & Total \\
\hline (A) Digestive tract and metabolism & 57 & 20.6 & $20.6(100.0)$ \\
\hline (C) Cardiovascular system & 9 & 3.2 & $3.2(100.0)$ \\
\hline (D) Dermal medicines & 41 & 14.8 & $14.8(100.0)$ \\
\hline (G) Genito-urinary system and sexual hormones & 6 & 2.2 & $2.2(100.0)$ \\
\hline (M) Muscle-skeletal system & 74 & 26.7 & $26.7(100.0)$ \\
\hline (N) Nervous system & 54 & 19.5 & $19.5(100.0)$ \\
\hline (P) Antiparasitic products, insecticides and insect repellent & 9 & 3.2 & $3.2(100.0)$ \\
\hline (R) Respiratory system & 77 & 27.8 & $27.8(100.0)$ \\
\hline (S) Sense organs & 9 & 3.2 & $3.2(100.0)$ \\
\hline
\end{tabular}


receiving drug therapy, were medicines for the respiratory system $(27.8 \%)$, for the muscle-skeletal system $(26.7 \%)$, for the digestive tract and metabolism $(20.6 \%)$, for the nervous system $(19.5 \%)$ and dermatological drugs (14.8\%) (Table 2).

Of the 298 patients included in the sample, all agreed to participate in the second phase of the study, giving their contact details. Of these, the pharmacist successfully contacted 268 patients $(89.9 \%)$. The remaining 30 patients were lost to follow-up.

The communication method most used between pharmacist and patients to assess the outcome of pharmaceutical counseling was the telephone $(n=161,60.1 \%)$, but a still considerably high proportion was evaluated face-to-face $(n=107$; $39.9 \%$ ). Yet it is noteworthy that when evaluating outcomes face-to-face, there was a statistically significant smaller number of patients who reported to have improved little or nothing their symptoms ( $25.2 \%$ and $8.4 \%$ respectively), whereas most of the patients that reported to have greatly improved their symptoms did so over a telephone assessment $(p<0.001)$.

Therefore, the following results are presented for a total of 268 patients. Of the 26 patients successfully contacted who had been referred to the doctor, 14 $(53.8 \%)$ had already had their medical appointment, whilst the remaining $12(46.2 \%)$ were still waiting.
Of all the patients who participated in the second phase of the study, regardless of the pharmaceutical intervention performed, 216 patients $(80.6 \%)$ reported that they improved greatly their symptoms after one week, while 52 patients $(19.4 \%)$ had improved little or nothing.

Of the 242 patients that received pharmaceutical counseling, $210(86.8 \%)$ reported having greatly improved their symptoms, whereas of the 14 patients who had a medical appointment, $6(42.9 \%)$ also reported to have greatly improved their symptoms.

The 32 patients $(13.2 \%)$ that did not improve or slightly improved their symptoms through pharmaceutical counseling were referred to medical or new pharmaceutical intervention which was not recorded due to the end of the study period.

Hence, one might say that the impact of pharmaceutical counseling was positive in $86.8 \%$ of patients $\left(210 /(242)^{*} 100 \%\right)$, and was negative in $13.2 \%$ of patients $(32 /(242) * 100 \%)$.

Results from the sensitivity analysis indicate that this value may vary from $77.5 \%$ of patients $\left(210 /(271)^{*} 100 \%\right)$, assuming that all patients lost to follow-up are considered untreated, to $88.2 \%$ $(239 /(271) * 100 \%)$, assuming that all are considered treated.

The study main results are schematically illustrated shown in Figure 1 which represents the flowchart of patient recruitment.

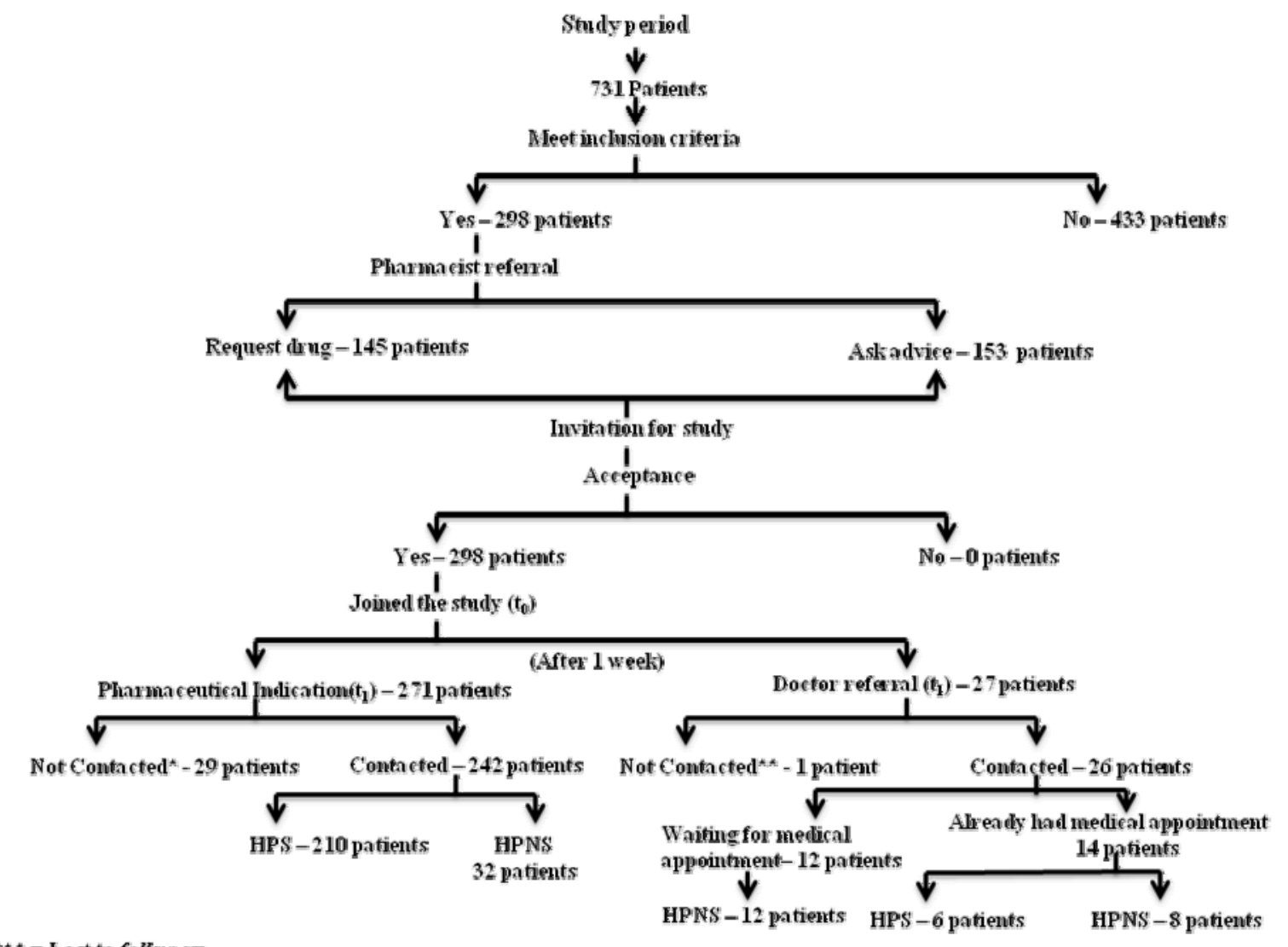

${ }^{*+\star \star *}=$ Lest to follow-ifg

HPS $=$ Health Problem Solved

HPNS $=$ Health Problem Not Solved

Figure 1. Summary flowchart of the main results of the study. 


\begin{tabular}{|c|c|c|c|c|c|c|}
\hline & $\begin{array}{c}\text { Direct-product } \\
\text { request }\end{array}$ & $\begin{array}{c}\text { Symptom-based } \\
\text { request }\end{array}$ & $p$-value & HPU & HPS & p-value \\
\hline Gender & $\mathrm{n}(\%)$ & $\mathrm{n}(\%)$ & & $\mathrm{n}(\%)$ & n (\%) & \\
\hline Female & $81(45.3)$ & $98(54.7)$ & \multirow{2}{*}{$0.149^{a}$} & $18(11.8)$ & $134(88.2)$ & \multirow{2}{*}{$0.410^{a}$} \\
\hline Male & $64(53.8)$ & $55(46.2)$ & & $14(15.6)$ & $76(84.4)$ & \\
\hline & $\mu(\mathrm{SD})$ & $\mu(\mathrm{SD})$ & & $\mu(\mathrm{SD})$ & $\mu(\mathrm{SD})$ & \\
\hline Age & $47.82(21.93)$ & $42.01(22.56)$ & $0.025^{b}$ & $45.93(23.88)$ & $43.64(22.07)$ & $0.589^{b}$ \\
\hline
\end{tabular}

Notes: $\mu$ - average; SD - standard deviation; ${ }^{a}$ Chi-square test; ${ }^{b}$ Student $t$ Test. HPU=Health Problem Unsolved, HPS=Health Problem Solved.

Patient's gender was unrelated with the presenting intention at the pharmacy (direct product request or symptom based request) $(p=0.149)$. In contrast, age was associated with the presenting behavior $(p=0.025)$, where younger patients more frequently requested for pharmaceutical counseling (average $=42.01, \mathrm{SD}=22.564)$, (Table 3).

Patients' socio-demographic (gender and age) characteristics did not influence the outcome of the pharmaceutical counseling $(p=0.410, p=0.589$ for gender and age, respectively) (Table 3 ). The baseline clinical characteristics, i.e., minor health problem reported by patients when presenting at the pharmacy, did also not influence the resolution of the problem $(p=0.233)$ (Table 4). However, data indicates that patients with digestive health problems $(92.7 \%)$, nervous system problems $(90.9 \%)$, skin problems $(85.4 \%)$ and respiratory problems (84.2\%) improved greatly after pharmaceutical counseling.

The type of pharmaceutical intervention influenced the resolution of the patient's health problem, where it was observed that $23.1 \%$ of patients referred for a medical appointment solved their health problem and $86.8 \%$ of patients immediately counseled by the pharmacist solved their health problem within the time frame considered $(p<0.001)$ (Table 4).

\section{DISCUSSION}

The main findings of this study were that during the study period, the prevalence of self-medication in Vila Nova de Milfontes was $40.7 \%$. Most patients presented themselves with a symptom-based request $(51.3 \%)$. Regardless of the presenting situation, $90.9 \%$ received pharmaceutical counseling and only a minority was referred to the doctor. After one week of pharmaceutical intervention, $86.8 \%$ had a positive impact.

The pharmaceutical counseling proved to be an area where investment should be made in different fields since about $40 \%$ of the patients who attended the pharmacy are potential candidates.
The prevalence of self-medication was significantly higher than the values reported by Nunes de Melo ${ }^{7}$ and Martins ${ }^{6}$, which can be due to various factors, including those that may be related to reduced demand for family physicians, in this case the low number of doctors available in Vila Nova de Milfontes during the study period, the recent increase in moderating fees (a term used to regulate access to the Portuguese National Health Service) and the different criteria used in the study methodology, including the selected definition of a self-medication situation. Given that the definition of self-medication is not universal, varying according to the author, the comparability of data obtained from the published literature has become quite limited.

In addition, it is likely that an increased attention bias has occurred since the main researcher involved in the study was the pharmacist who recruited the patient sample, whereas in previous studies the recruitment was done by several pharmacists. Therefore, it may be expected that motivation was higher in the current study.

Regarding distribution of self-medication by demographic characteristics, both gender and age distribution, were consistent with previous studies. ${ }^{4,6,7,35,36}$

The most frequent health problems were similar to those reported by Stein ${ }^{35}$, Csilla Major ${ }^{36}$, Kerry Wilbur $^{37}$ and consistent with studies elapsed in Portugal. $^{17,29}$ The analyzed literature ${ }^{17-19,28}$ are mostly in accordance with the order of prevalence of more frequent health problems, i.e., problems of respiratory health and medicines for the respiratory system were the most frequent in most studies presented.

Nonetheless, one must consider that seasonality influences the prevalence of some of these problems, namely the respiratory, which have higher expression at this time of the year. Exception made to fever, which was reported by a very small number of cases $(2.0 \%)$ considering the time of the year when the study was conducted. This fact may

\begin{tabular}{|c|c|c|c|c|}
\hline \multicolumn{2}{|c|}{ Variable } & $\begin{array}{l}\mathrm{HPU}^{*} \\
\mathrm{n}(\%)\end{array}$ & $\begin{array}{l}\text { HPS }^{*} \\
\text { n (\%) }\end{array}$ & Value $p$ \\
\hline \multirow{5}{*}{ Presenting Health problem ${ }^{\star *}$} & Respiratory & $9(15.8)$ & $48(84.2)$ & \multirow{5}{*}{$0.233^{\mathrm{c}}$} \\
\hline & Digestive & $3(7.3)$ & $38(92.7)$ & \\
\hline & Dermal & $7(14.6)$ & $41(85.4)$ & \\
\hline & Muscle or bone & $7(28.0)$ & $18(72.0)$ & \\
\hline & Nervous system & $2(9.1)$ & $20(90.9)$ & \\
\hline \multirow{2}{*}{ Type of pharmaceutical intervention } & Medical referral & $20(76.9)$ & $6(23.1)$ & \multirow{2}{*}{$<0.001^{\mathrm{a}}$} \\
\hline & Pharmaceutical indication & $32(13.2)$ & $210(86.8)$ & \\
\hline
\end{tabular}


Table 5: Comparison of socio-demographic characteristics of the sample with the reference population $n(\%)$

\begin{tabular}{|rr|c|c|}
\hline \multicolumn{2}{|c|}{ Characteristic } & Sample & $\begin{array}{c}\text { Reference } \\
\text { population* }\end{array}$ \\
\hline Gender & Female & $179(60.1)$ & $2551(50.70)$ \\
& Male & $119(39.9)$ & $2480(49.30)$ \\
\hline Age group & & & \\
& $15-24$ & $42(14.10)$ & $478(11.38)$ \\
& $25-64$ & $185(62.10)$ & $2789(66.39)$ \\
& 65 or more & $71(23.80)$ & $934(22.23)$ \\
\hline
\end{tabular}

*Notes: Censos 2011 - Resultados Definitivos Alentejo, Instituto Nacional de Estatística. Portugal. Available at: http://www.ine.pt. The age group $<15$ years was not considered because it was na exclusion criteria of the study. Therefore data presented assumes that $100 \%$ of the reference population is over 15 years of age.

be explained by the definition adopted for the present study, which considered fever only in the cases where patients had confirmed their body temperature. This methodological option may possibly be considered open for discussion since the self-diagnosis of the other minor symptoms did not require any confirmation, namely observation of the throat or ears.

Perhaps the most interesting and motivating result of the current study is the high proportion of patients $(86.8 \%)$ that perceived the pharmaceutical intervention to have a positive impact on their health-related problems. In a study by Nicole Bosse, similar results have been presented with $82.6 \%$ of an 83-patient sample reporting great relief following one week of pharmaceutical intervention. ${ }^{4}$

This study is valuable for various reasons. Firstly, the sample obtained superseded the sample size estimated and additionally socio-demographic characteristics of the sample were very similarly distributed to the reference population (Table 5), indicating the sample was representative. ${ }^{28}$ Secondly, it focuses on a little researched area, albeit very common in daily practice. Community pharmacists put great effort on providing excellent care to their patients, but researchers seem to fail demonstrating its value. As such, there have been countries that for decades now have demonstrated the value of various pharmaceutical services and have even gained recognition of their importance by achieving remuneration, such as the case of Switzerland, The Netherlands and Denmark, to name a few. ${ }^{27}$ Portugal has not yet been able to do so. This project will certainly provide a modest contribution for the recognition of an important pharmaceutical service with demonstrated positive health outcome.

Nonetheless, it must be acknowledged that the study also has important limitations. Firstly, the study design chosen is not the ideal to demonstrate with high degree of evidence the value of the pharmaceutical intervention, as a RCT or a community trial would be a better approach. Indeed, given the fact that the health problems are selflimiting conditions, a control group would be needed to provide indisputable evidence that the improvement in patients' health status can be attributed to the pharmaceutical intervention. Additionally, internal factors, such as medication adherence, and other external factors, such as resorting to complementary medicine, may have contributed to clinical improvement, that without such designs one could not control for. However, conducting a RCT would have ethical implications that would invalidate its carrying out in a single pharmacy with a single pharmacist and the community trial approach would imply involving more pharmacies, which was not feasible given the timeline of the study (MSc project).

Additionally, it should be noted that if one wished to compare the effectiveness of the pharmaceutical intervention with the medical one, the time period would have had to be extended beyond 7 days. If such was the case, one would also need a larger number of medical referrals, as these were clearly few in the current study.

It was not the intention of this study to assess the sustainability of the pharmaceutical counseling in clinical terms. Nevertheless, it would be interesting to do it and in doing so the period of patients' followup had equally to be extended.

The short time period of the study also failed to evaluate patients that were waiting for a medical appointment and the outcome of therapy prescribed to 8 patients $(57.1 \%)$ which began their treatments very near of the 7th day of the pharmaceutical review.

It must be recognized that some of the outcomes intended to measure are not achievable after one week. An example is the case of acquisition of vitamins for the prevention of vitamin deficiencies (avitaminosis), it is impossible for the patient to have any perception of the drug's efficacy (or lack of it) after one week and therefore may not report the problem to have been solved. This may have negatively influenced the presented results. However, this aspect is negligible since only 8 patients $(2.7 \%)$ reported this health problem. Still, one must consider that this pharmacotherapeutic class should be excluded in future studies examining the outcomes of pharmaceutical intervention.

Another limitation of the study was that the questionnaire was not tested and it became inconsistent in the assessment criteria of multiple health problems, i.e., when the patient reported more than one presenting condition, the outcome was assessed in a holistic manner. Still, this fact is not relevant since only $8 \%$ of the sample reported having more than one health problem. However, one did not evaluate if during the course of the study additional health problems have arisen.

An important limitation is that existing protocols do not cover all spectra of pharmaceutical counseling and not all of those existing are validated. Hence the therapeutic options made may be criticized as they are not universally recognized, which limits the comparison to studies by other authors.

Finally, it is important to reflect on the potential biases in interpreting the study's main result, which indicates an extremely high impact of pharmaceutical counseling. It is widely reported that there is a tendency for patients to attempt to 
transmit a socially acceptable image, avoiding critical situations test (social desirability bias). This phenomenon may be exacerbated if the evaluator is also their usual pharmacist, possibly leading them to more likely report on improving minor symptoms in an effort to please their caregiver, which was the case.

Additionally, it should be stated that the fact that there were significant differences on the level of improvement reported when comparing face-to-face and telephone assessment is cause of concern and may have two explanations. Patients assessed over the phone were those that did not return to the pharmacy, and therefore may be expected to be those perceiving greater improvement. On the other hand, if one assumes there was social desirability bias, then one could expect that this were more evident face-to-face, which was not the case. Either way, in future studies, for purposes of internal validity the method of assessment should be the same for all patients.

Another aspect briefly mentioned but worth highlighting, is that the conditions studied are selflimiting, so in fact one cannot ensure that health improvement was a direct result of the pharmaceutical counseling. ${ }^{38}$ However, one cannot also rule out the possibility that the pharmaceutical counseling led to quicker recovery, an issue worth exploring in future studies involving a control group.

For all the above mentioned reasons, one cannot state there is certainly a causal relationship between pharmaceutical counseling and patients' outcomes. However, this establishes strong hypothesis on such relationship that need further evidence by stronger study designs.

The process of pharmaceutical counseling should ideally take place in a private office; however, this would not reflect daily practice and for such reason counseling in this study was done mainly at the counter. The downside to such approach is that it may have restricted the depth of the initial assessment and non-pharmacological advice provided.

Nonetheless, the presented data indicates that pharmaceutical counseling led to consistent results for all patients regardless of their gender and age and of the type of presented minor health problem. The main difference found in outcomes was that the type of pharmaceutical intervention influenced the resolution of the patient's health problem, i.e., patients referred for medical appointment reported a lower proportion of positive outcomes. One explanation for this was due to the shortage of doctors, the waiting time for medical appointment and the short study period to continue to obtain more clinical results. Further studies to evaluate the effectiveness of evidence-based NPMs would also be needed, its long-term impact and costeffectiveness of this type of pharmaceutical intervention. ${ }^{39}$ As well as studies assessing the behavior of the community pharmacist in their daily practice, with the aim of being able to implement training to improve their counseling to the patient. 40,41
Despite all limitations mentioned, it should be acknowledged that the research aims were met and it could be demonstrated that the pharmaceutical intervention in this study contributed to the prevention and treatment of most minor health problems of patients attending community pharmacy under a self-medication situation.

\section{CONCLUSIONS}

This study demonstrates that the proportion of individuals who resorted to self-medication in Vila Nova de Milfontes was $40.7 \%$. Thus it can be said that almost half of the patients of a pharmacy are potential candidates for pharmaceutical counseling. The results showed that $86.8 \%$ of patients improved their minor health symptoms. This means that the pharmaceutical intervention, consisting of the selection of the most appropriate therapy and the provision of information, resulted in better self-care for a vast majority of patients.

\section{CONFLICT OF INTEREST}

There are no conflicts of interests to be declared.

\section{IMPACTO DEL CONSEJO FARMACÉUTICO EN PROBLEMAS DE SALUD MENORES EN PORTUGAL RURAL}

\section{RESUMEN}

Objetivos: Los objetivos de este estudio fueron determinar la prevalencia de auto-medicación y evaluar el impacto clínico del consejo farmacéutico.

Métodos: Se utilizó un estudio transversal con un componente predictivo para evaluar el impacto del consejo farmacéutico. El estudio se realizó en una farmacia comunitaria rural durante 14 días consecutivos en diciembre de 20012, reclutando a todos los individuos que aceptaron participar y cumplían los criterios de elegibilidad. Durante una entrevista presencial directa se registró los datos demográficos y clínicos, seguido de una intervención farmacéutica que consistía en evaluar los síntomas, seleccionar el medicamento sin receta (NPM) disponible más adecuado, y aconsejar al paciente sobre medidas farmacológicas y no farmacológicas, de acuerdo a protocolos establecidos para síntomas menores. Cuando era adecuado, se refería al paciente al médico. Una semana más tarde, se medía el resultado clínico de la intervención preguntando a los pacientes por la resolución de sus problemas de salud menores.

Resultados: Se analizaron datos de 298 pacientes, la mayoría eran mujeres $(60,1 \%)$ con una edad media de 44,84 años $(\mathrm{DE}=22,41)$. Los problemas respiratorio serán los más frecuentes $(\mathrm{n}=78 ; 26.2 \%)$, y los medicamentos del tracto respiratorio la medicación más frecuentemente indicada $(\mathrm{n}=77 ; 27.8 \%)$. La prevalencia observada de auto-medicación fue del 40,7\%. De los 271 pacientes beneficiarios del consejo farmacéutico, el 86,8\% tenía problemas de salud menores que se resolvieron tras una semana (oscilando del 77,5\% al 88,2\% de acuerdo a un análisis de sensibilidad para las pérdidas).

Conclusiones: Este trabajo es importante ya que demuestra el impacto beneficioso del consejo farmacéutico, un área muy importante y en la que la literatura farmacéutica es particularmente escasa.

Palabras clave: Medicamentos sin Prescripción; Consejo; Servicios de Farmacia Comunitaria; Práctica Profesional; Farmacéuticos; Portugal 
1. Soares MA. Medicamentos não prescritos - aconselhamento farmacêutico. Associação Nacional das Farmácias. Publicações Farmácias Portuguesas, Lisboa. 2002; 2a edição: 27-114.

2. Despacho n¹7690/2007, de 23 de Julho. INFARMED - Gabinete Jurídico e Contencioso. Legislação Farmacêutica Compilada. Lisboa.

3. Naves J, Castro L, Carvalho C, Merchán-Hamann E. Self-medication: a qualitative approach of its motivations. Cien Saude Colet. 2010;15(Suppl 1):1751-1762

4. Bosse N, Machado M, Mistry A. Efficacy of an over-the-counter intervention follow-up program in community pharmacies. J Am Pharm Assoc (2003). 2012;52(4):535-540. doi: 10.1331/JAPhA.2012.10093

5. Decreto-Lei n. ${ }^{\circ}$ 176/2006, de 30de Agosto. INFARMED - Gabinete Jurídico e Contencioso. Legislação Farmacêutica Compilada. Lisboa.

6. Martins A, Miranda A, Mendes Z, Soares M, Ferreira P, Nogueira A. Self-medication in a Portuguese urban population: a prevalence study. Pharmacoepidemiol Drug Saf. 2002;11(5):409-414.

7. Melo M, Madureira B, Ferreira A, Mendes Z, Miranda A, Martins A. Prevalence of self-medication in rural areas of Portugal. Pharm World Sci. 2006;28(1):19-25.

8. Figueiras A, Caamaño F, Gestal Otero-JJ. Sociodemographic factors related to self-medication in Spain. Eur J Epidemiol. 2000;16(1):19-26.

9. Schimd B, Bernal R, Silva NN. Self-medication in low-income adults in Southeastern Brazil. Rev Saude Publica. 2010;44(6):1039-1045.

10. Vosgerau MZ, Soares DA, Souza RK, Matsuo T, Carvalho GS. Consumption of medicines by adults within an area covered by a family health unit. Latin Am J Pharm. 2011;16(1):1629-1638.

11. Ordem dos Farmacêuticos. Boas Práticas Farmacêuticas para a farmácia comunitária. Conselho Nacional da Qualidade. 2009; $3^{\mathrm{a}}$ edição.

12. Ordem dos Farmacêuticos. Linhas de orientação - Indicação Farmacêutica. Elaborado pelo Grupo das Boas Práticas de Farmácia - Grupo do Guincho, Fevereiro 2006.. Available at: http://www.ordemfarmaceuticos.pt (accessed in 10.11.2012)

13. Galán T. El rol del farmacéutico en automedicación. Uso de medicamentos: análisis desde la experiencia en España. Pharm Care Esp. 1999;1:157-164.

14. Faus MJ, Amariles P, Martínez Martinez F. Atención Farmacéutica - conceptos, procesos y casos práticos. Pharm Care Esp. 2007;8:85-106.

15. Centro Andaluz de Documentación e Información del Medicamento. Automedicación: Riesgos y benefícios. Boletín Terapeutico Andaluz. 1996;12(5):17-18.

16. Krishnan HS, Schaefer M. Evaluation of the impact of pharmacist's advice giving on the outcomes of self-medication in patients suffering from dyspepsia. Pharm World Sci. 2000;22(3):102-108.

17. Sclar DA, Robison LM, Skaer TL. Pharmacy consultation and over-the-counter medication purchasing outcomes. J Clin Pharm Ther. 1996;21(3):177-184.

18. Benrimoj SI, Werner JB, Raffaele C, Roberts AS, Costa FA. Monitoring quality standards in the provision of nonprescription medicines from Australian Community Pharmacies: results of a national programme. Qual Saf Health Care. 2007;16(5):354-358.

19. Wazaify M, Al-Bsoul-Younes A, Abu-Gharbieh E, Tahaineh L. Societal perspectives on the role of community pharmacists and over-the-counter drugs in Jordan. Pharm World Sci. 2008 Dec;30(6):884-91. doi: 10.1007/s11096-0089244-1

20. You JH, Wong FY, Chan FW, Wong EL, Yeoh E. Public perception on the role of community pharmacists in selfmedication and self-care in Hong Kong. BMC Clin Pharmacol. 2011;11:19. doi: 10.1186/1472-6904-11-19

21. Holland R, Desborough J, Goodyer L, Hall S, Wright D, Loke YK. Does pharmacist-led medication review help to reduce hospital admissions and deaths in older people? A systematic review and meta-analysis. Br J Clin Pharmacol. 2008;65(3):303-316.

22. Royal S, Smeaton L, Avery AJ, Hurwitz B, Sheikh A. Interventions in primary care to reduce medication related adverse events and hospital admissions: systematic review and meta-analysis. Qual Saf Health Care. 2006;15(1):23-31.

23. Patterson SM, Hughes C, Kerse N, Cardwell CR, Bradley MC. Interventions to improve the appropriate use of polypharmacy for older people. Cochrane Database Syst Rev. 2012;5:CD008165. doi: 10.1002/14651858.CD008165.pub2

24. Christensen M, Lundh A, Medication review in hospitalised patients to reduce morbidity and mortality. Cochrane Database Syst Rev. 2013;2:CD008986. doi: 10.1002/14651858.CD008986.pub2

25. Ryan R, Santesso N, Lowe D, Hill S, Grimshaw J, Prictor M, Kaufman C, Cowie G, Taylor M. Interventions to improve safe and effective medicines use by consumers: an overview of systematic reviews. Cochrane Database Syst Rev. 2014;4:CD007768. doi: 10.1002/14651858.CD007768.pub3

26. Martins S, Costa FA, Caramona M. Implementação de cuidados Farmacêuticos em Portugal, seis anos depois. Rev Port Farmacoter. 2013;5:7-15

27. Hughes CM, Hawwa AF, Scullin C, Anderson C, Bernsten CB, Bjornsdóttir I, Cordina MA, Costa FA, Wulf ID, Eichenberger P, Foulon V, Henman MC, Hersberger KE, Schaefer MA, Sondergaard B, Tully MP, Westerlund T, McElnay JC. Provision of pharmaceutical care by community pharmacists: a comparison across Europe. Pharm World Sci. 2010;32(4):472-87. doi: 10.1007/s11096-010-9393-x 
28. Censos 2011 - Resultados Definitivos Alentejo, Instituto Nacional de Estatística. Portugal. Available at: http://www.ine.pt (accessed in 10.11.2012).

29. Watson MC, Bond CM, Grimshaw JM, Johnston M. Factors predicting the guideline compliant supply (or non-supply) of non-prescription medicines in the community pharmacy setting. Qual Saf Health Care. 2006;15(1):53-57.

30. Garner M, Watson MC. Using linguistic analysis to explore medicine counter assistants' communication during consultations for nonprescription medicines. Patient Educ Couns. 2007;65(1):51-57.

31. Soares MA. Automedicação versus indicação farmacêutica. Mundo Farmacêutico, n¹8; 2005.

32. Ordem dos Farmacêuticos. Indicação Farmacêutica no uso racional dos medicamentos não sujeitos a receita médica. Protocolo da Febre. Linhas de Orientação. 2006; Lisboa. Consulted in 01.11.2012. Available at: http://www.ordemfarmaceuticos.pt (accessed in 10.11.2012).

33. Boletins de Farmácia Prática.. Available at: http://www.anfonline.pt (accessed in 10.11.2012).

34. World Health Organization. Guidelines for ATC classification and DDD assignment 2013. Norwegian Institute of Public Health. Oslo; WHO:2012.

35. Stein CM, Gora NP, Macheka BM. Self-medication in urban and rural Zimbabwean communities. Br J Clin Pharmacol. 1989;27(6):741-747.

36. Major $\mathrm{C}$, Vincze Z. Consumer habits and interests regarding non-prescription medications in Hungary. Fam Pract. 2010;27(3):333-8. doi: 10.1093/fampra/cmp105

37. Wilbur K, Salam SE, Mohammadi E. Patient perceptions of pharmacist roles in guiding self-medication of over-thecounter therapy in Qatar. Patient Prefer Adherence. 2010;4:87-93.

38. Rutter $P$, Wadesango $E$. Does evidence drive pharmacist over-the-counter product recommendations? J Eval Clin Pract. 2014;20(4):425-8. doi: 10.1111/jep.12157

39. Ngwerume K, Watson M, Bond C, Blenkinsopp A. An evaluation of an intervention designed to improve the evidencebased supply of non-prescription medicines from community pharmacies. Int J Pharm Pract. 2014 May [Epub ahead of print].

40. Mesquita AR, de Oliveira Sá DA, Santos AP, de Almeida Neto A, Lyra DP Jr. Assessment of pharmacist's recommendation of non-prescription medicines in Brazil: asimulated patient study. Int J Clin Pharm. 2013;35(4):647655. doi: 10.1007/s11096-013-9787-7

41. Xu T, de Almeida Neto AC, Moles RJ. A systematic review of simulated-patient methods used in community pharmacy to assessthe provision of non-prescription medicines. Int J Pharm Pract. 2012;20(5):307-319. doi: 10.1111/j.20427174.2012.00201.x 